\title{
Glutathione- and Cysteine-Induced Transverse Overgrowth on Gold Nanorods
}

Xiaoshan Kou, Shuzhuo Zhang, Zhi Yang, Chia-Kuang Tsung, Galen D. Stucky, Lingdong Sun, Jianfang Wang, and Chunhua Yan

\section{Supporting Information}

Table S1. Average Sizes of Gold Nanorods Grown under Varying Experimental Conditions

\begin{tabular}{|c|c|c|c|}
\hline growth conditions & diameter $(\mathrm{nm})^{a}$ & length $(\mathrm{nm})^{a}$ & aspect ratio $^{a}$ \\
\hline original Au nanorods & $10.3(0.9)$ & $36(4)$ & $3.5(0.5)$ \\
\hline $\begin{array}{l}2.5 \mathrm{~mL} \text { original Au nanorod solution, } 100 \mu \mathrm{M} \\
\text { glutathione, } 2 \mathrm{~mL} \text { growth solution }\end{array}$ & $14(2)$ & $39(5)$ & $2.9(0.4)$ \\
\hline $\begin{array}{l}2.5 \mathrm{~mL} \text { original Au nanorod solution, } 100 \mu \mathrm{M} \\
\text { glutathione, } 3 \mathrm{~mL} \text { growth solution }\end{array}$ & $15(2)$ & $39(6)$ & $2.7(0.5)$ \\
\hline $\begin{array}{l}2.5 \mathrm{~mL} \text { original Au nanorod solution, } 100 \mu \mathrm{M} \\
\text { glutathione, } 5 \mathrm{~mL} \text { growth solution }\end{array}$ & $19(3)$ & $39(6)$ & $2.1(0.4)$ \\
\hline $\begin{array}{l}2.5 \mathrm{~mL} \text { original Au nanorod solution, } 100 \mu \mathrm{M} \\
\text { glutathione, } 7 \mathrm{~mL} \text { growth solution }\end{array}$ & $25(3)$ & $39(6)$ & $1.6(0.3)$ \\
\hline $\begin{array}{l}2.5 \mathrm{~mL} \text { original Au nanorod solution, } 100 \mu \mathrm{M} \\
\text { glutathione, } 12 \mathrm{~mL} \text { growth solution }\end{array}$ & $34(3)$ & $39(5)$ & $1.2(0.1)$ \\
\hline $\begin{array}{l}2.5 \mathrm{~mL} \text { original } \mathrm{Au} \text { nanorod solution, } 100 \mu \mathrm{M} \\
\text { glutathione, } 15 \mathrm{~mL} \text { growth solution }\end{array}$ & $35(2)$ & $39(10)$ & $1.1(0.3)$ \\
\hline $\begin{array}{l}2.5 \mathrm{~mL} \text { original Au nanorod solution, no } \\
\text { glutathione, } 3 \mathrm{~mL} \text { growth solution }\end{array}$ & $13(2)$ & $41(4)$ & $3.2(0.4)$ \\
\hline $\begin{array}{l}2.5 \mathrm{~mL} \text { original Au nanorod solution, no } \\
\text { glutathione, } 7 \mathrm{~mL} \text { growth solution }\end{array}$ & $17(2)$ & $46(7)$ & $2.8(0.4)$ \\
\hline $\begin{array}{l}2.5 \mathrm{~mL} \text { original Au nanorod solution, no } \\
\text { glutathione, } 15 \mathrm{~mL} \text { growth solution }\end{array}$ & $21(2)$ & $55(5)$ & $2.6(0.3)$ \\
\hline $\begin{array}{l}2.5 \mathrm{~mL} \text { original } \mathrm{Au} \text { nanorod solution, } 10 \mu \mathrm{M} \\
\text { glutathione, } 10 \mathrm{~mL} \text { growth solution }\end{array}$ & $20(2)$ & $50(5)$ & $2.4(0.3)$ \\
\hline $\begin{array}{l}2.5 \mathrm{~mL} \text { original } \mathrm{Au} \text { nanorod solution, } 50 \mu \mathrm{M} \\
\text { glutathione, } 10 \mathrm{~mL} \text { growth solution }\end{array}$ & $21(2)$ & $48(5)$ & $2.3(0.3)$ \\
\hline
\end{tabular}

${ }^{a}$ The numbers in the parentheses are standard deviations. Size measurements were performed on $200 \mathrm{Au}$ nanorods per sample from TEM images. 

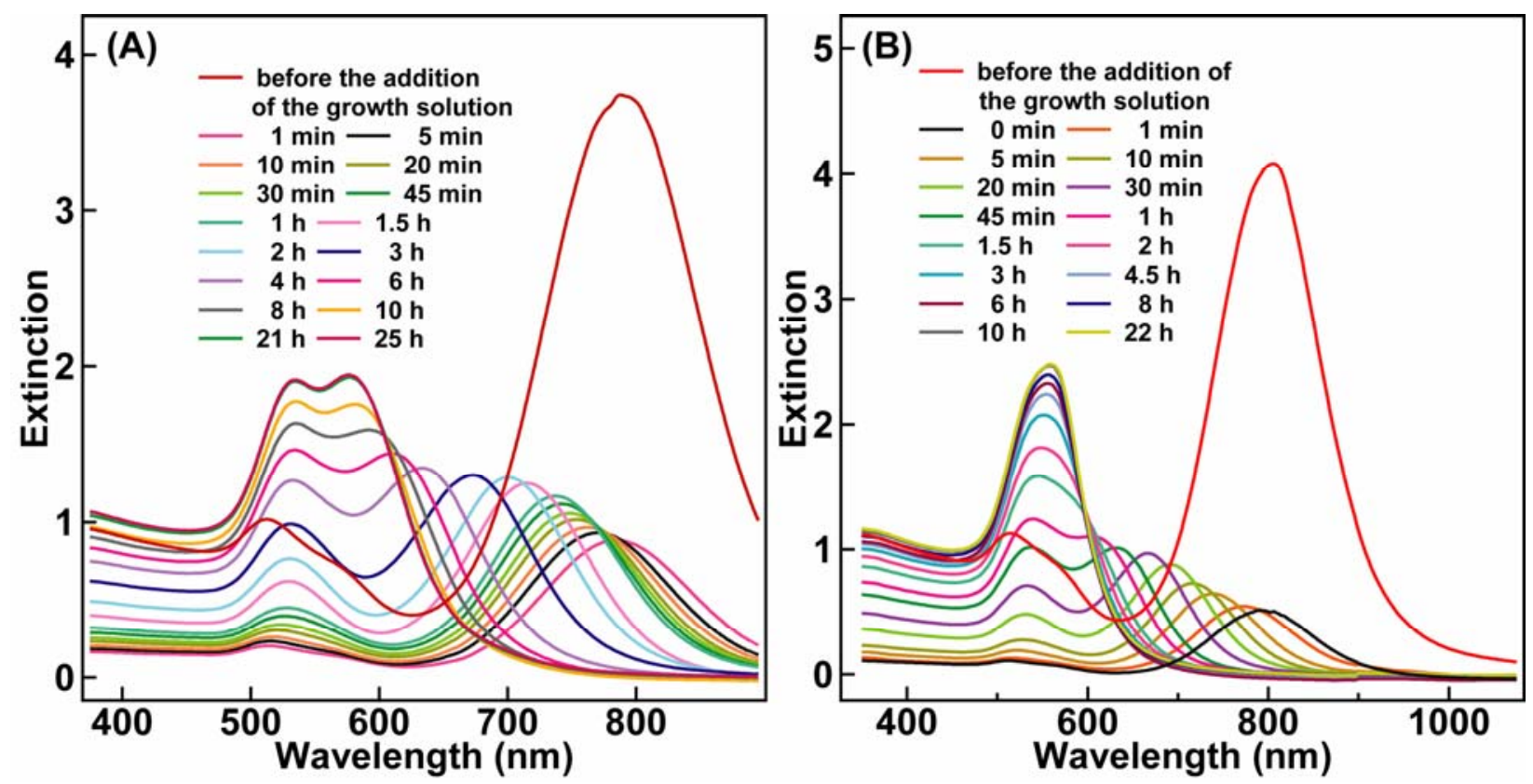

Figure S1. Extinction spectra recorded as a function of time after the addition of the growth solution into $2.5 \mathrm{~mL}$ aliquots of the original Au nanorod solution containing $100 \mu \mathrm{M}$ glutathione. The volumes of the growth solution for (A) and (B) are 7 and $15 \mathrm{~mL}$, respectively.

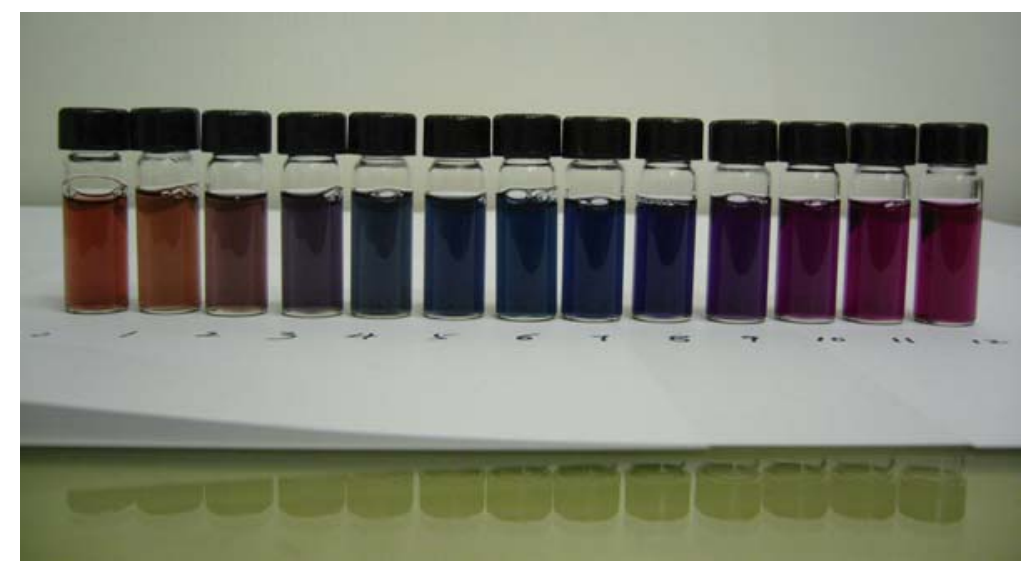

Figure S2. Digital picture of the growth products obtained from glutathione-induced overgrowth on Au nanorods. The samples denoted by the numbers from 0 to 12 correspond to the curves from (a) to (m) shown in Figure 2A. The picture was taken with a Panasonic digital camera (DMC FX9). 

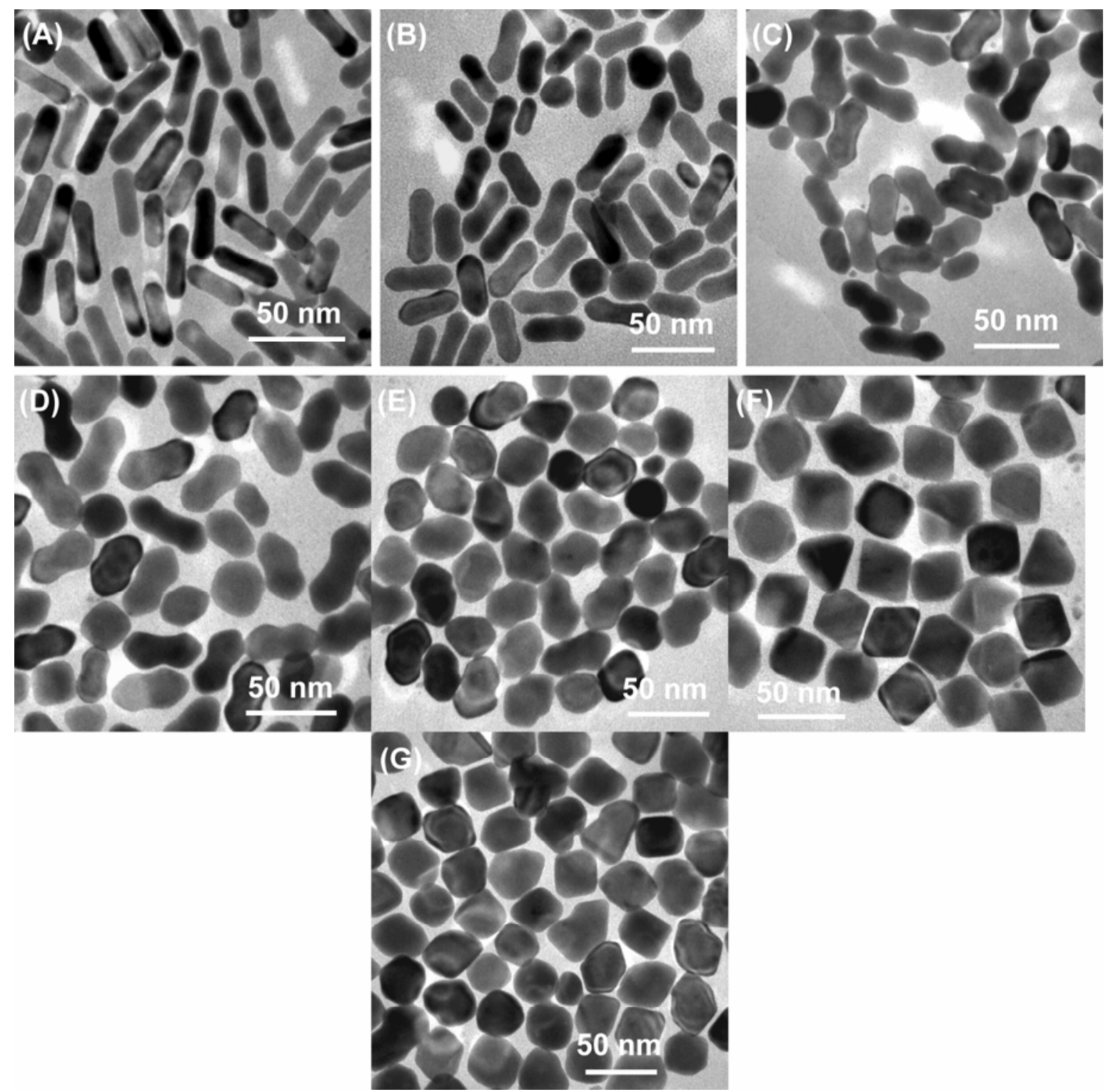

Figure S3. (A) TEM image of the original Au nanorods. (B) - (G) TEM images of the growth products corresponding to the samples (c), (d), (f), (h), (l), and (m) shown in Figure 2A, respectively. 

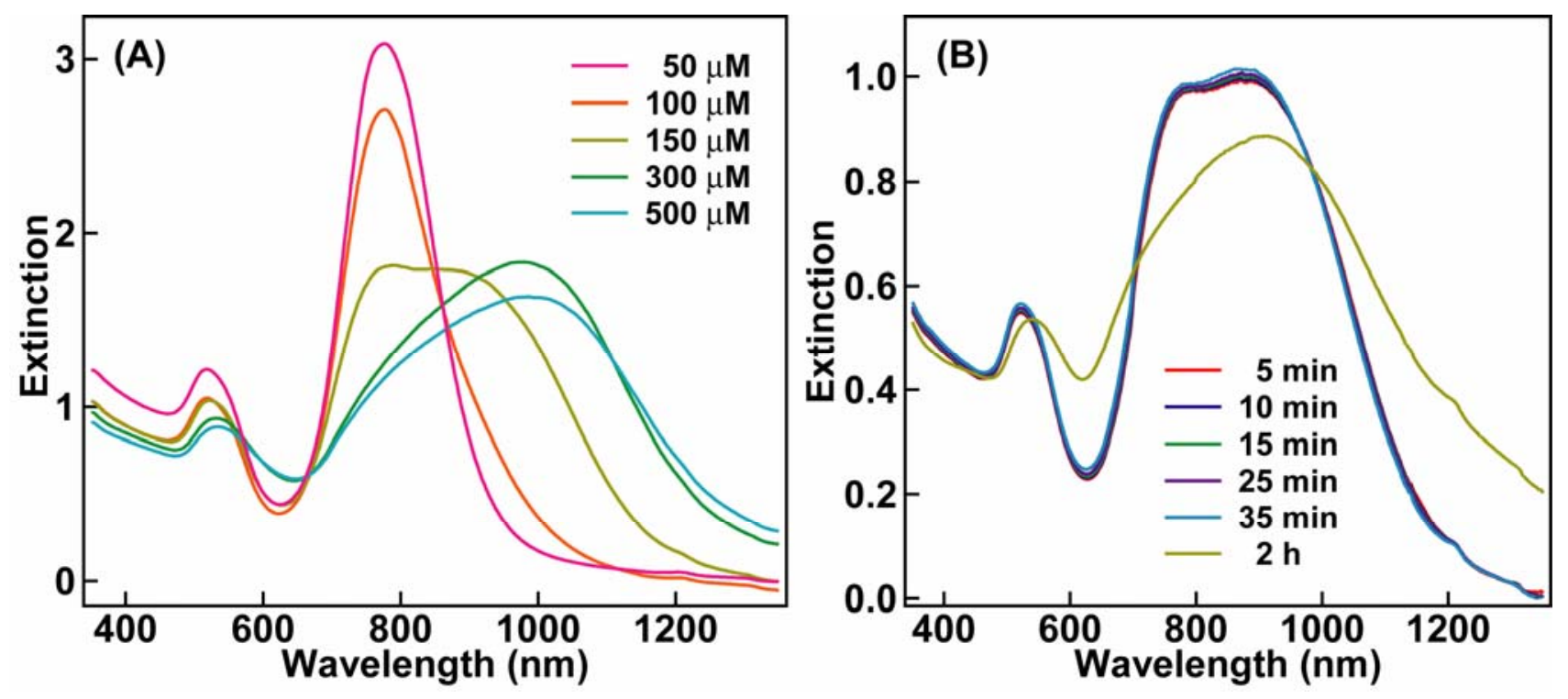

Figure S4. (A) Extinction spectra of the original Au nanorod solutions containing varying concentrations of glutathione. The appearance of a new extinction peak is due to glutathioneinduced end-to-end assembly of Au nanorods in the solutions. (B) Time-dependent extinction spectra recorded after the addition of $7 \mathrm{~mL}$ of the growth solution into $2.5 \mathrm{~mL}$ of the original $\mathrm{Au}$ nanorod solution containing $150 \mu \mathrm{M}$ glutathione. Both the transverse and longitudinal growth are blocked. The extinction spectral change after $2 \mathrm{~h}$ is due to the end-to-end assembly of $\mathrm{Au}$ nanorods.

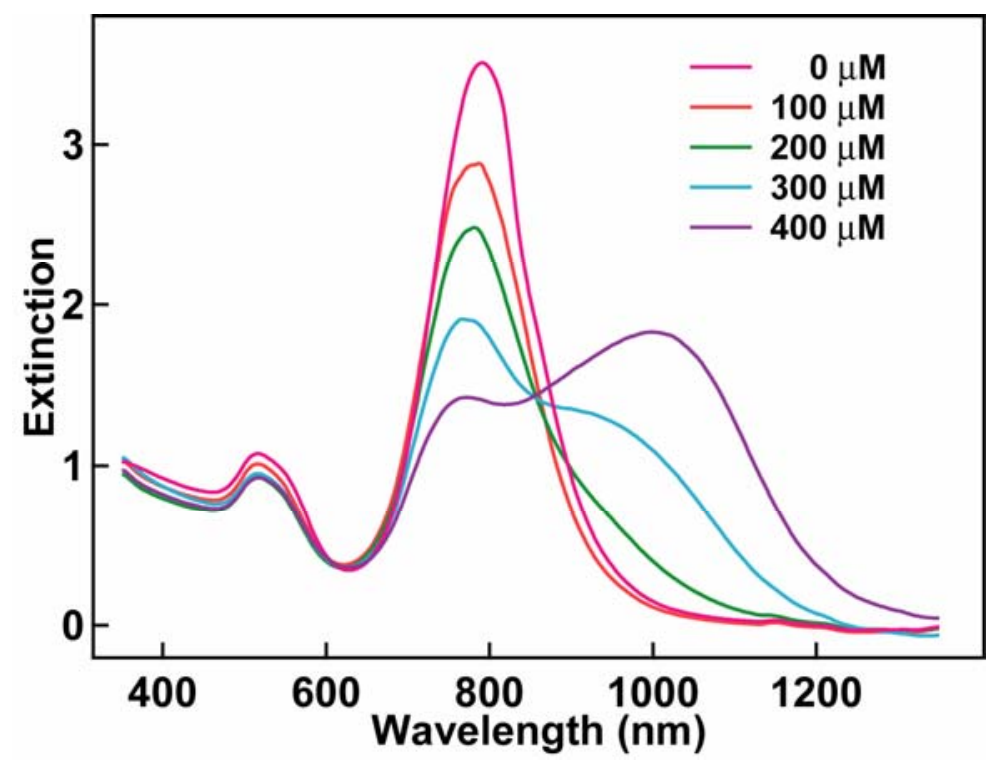

Figure S5. Extinction spectra of the original Au nanorod solutions containing varying concentrations of cysteine. The appearance of a new extinction peak at a longer wavelength is due to cysteine-induced end-to-end assembly of Au nanorods in the solutions. 

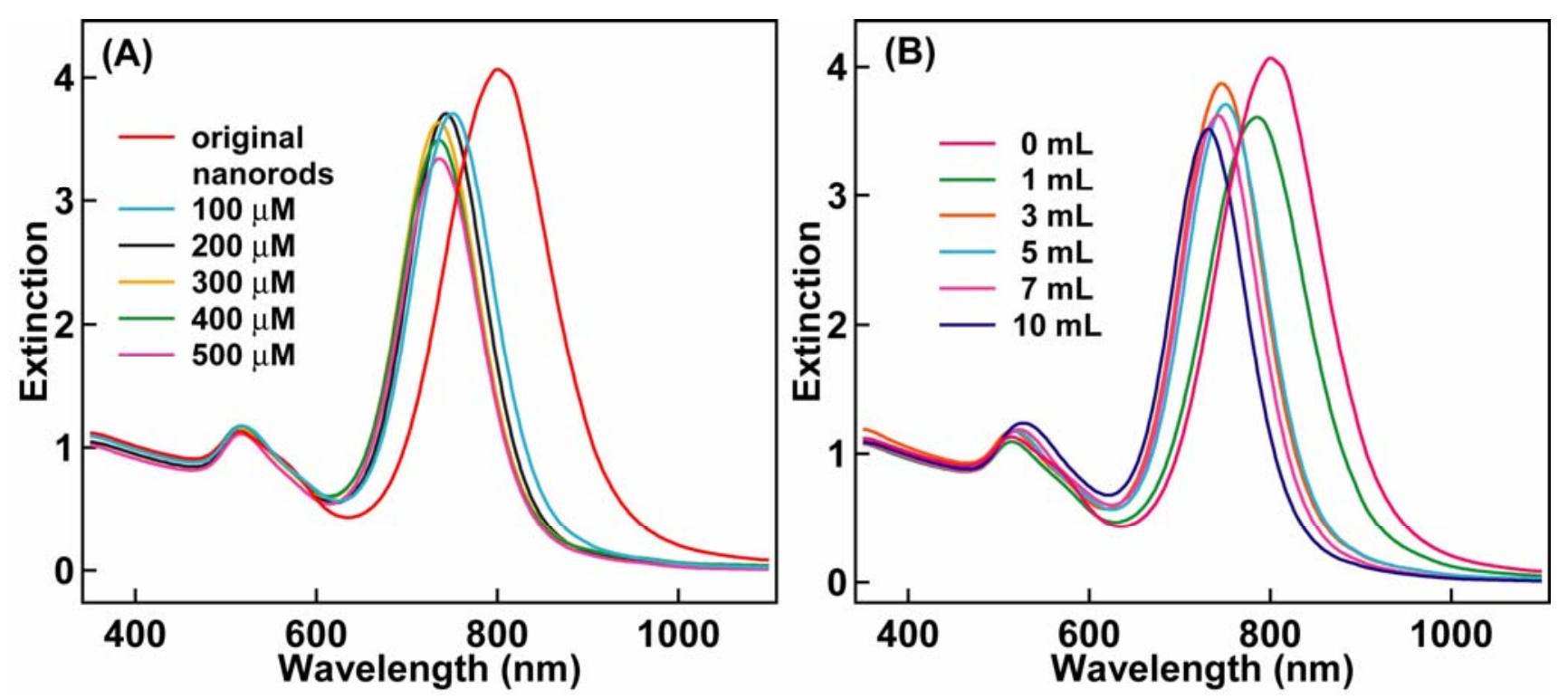

Figure S6. (A) Extinction spectra of the growth products obtained by the addition of $5 \mathrm{~mL}$ of the growth solution into $2.5 \mathrm{~mL}$ aliquots of the original $\mathrm{Au}$ nanorod solution containing 3mercaptopropionic acid at varying concentrations. (B) Extinction spectra of the growth products obtained by the addition of varying volumes of the growth solution into $2.5 \mathrm{~mL}$ aliquots of the original Au nanorod solution containing $200 \mu \mathrm{M}$ 3-mercaptopropionic acid. 

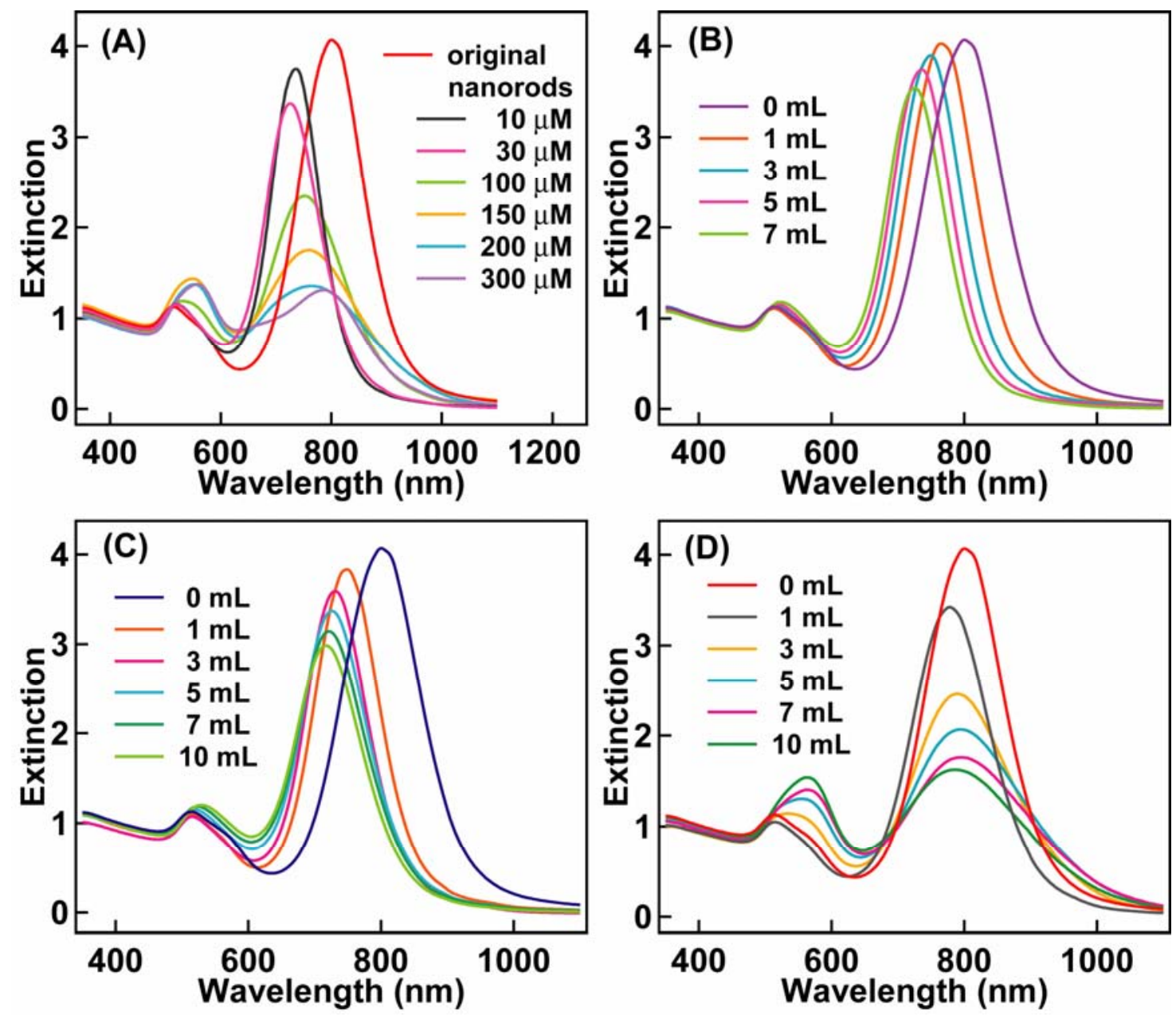

Figure S7. (A) Extinction spectra of the growth products obtained by the addition of $5 \mathrm{~mL}$ of the growth solution into $2.5 \mathrm{~mL}$ aliquots of the original Au nanorod solution containing 11mercaptoundecanoic acid at varying concentrations. (B) Extinction spectra of the growth products obtained by the addition of varying volumes of the growth solution into $2.5 \mathrm{~mL}$ aliquots of the original $\mathrm{Au}$ nanorod solution containing $10 \mu \mathrm{M}$ 11-mercaptoundecanoic acid. (C) Extinction spectra of the growth products obtained by the addition of varying volumes of the growth solution into $2.5 \mathrm{~mL}$ aliquots of the original Au nanorod solution containing $30 \mu \mathrm{M} 11$ mercaptoundecanoic acid. (D) Extinction spectra of the growth products obtained by the addition of varying volumes of the growth solution into $2.5 \mathrm{~mL}$ aliquots of the original $\mathrm{Au}$ nanorod solution containing $100 \mu \mathrm{M}$ 11-mercaptoundecanoic acid. 

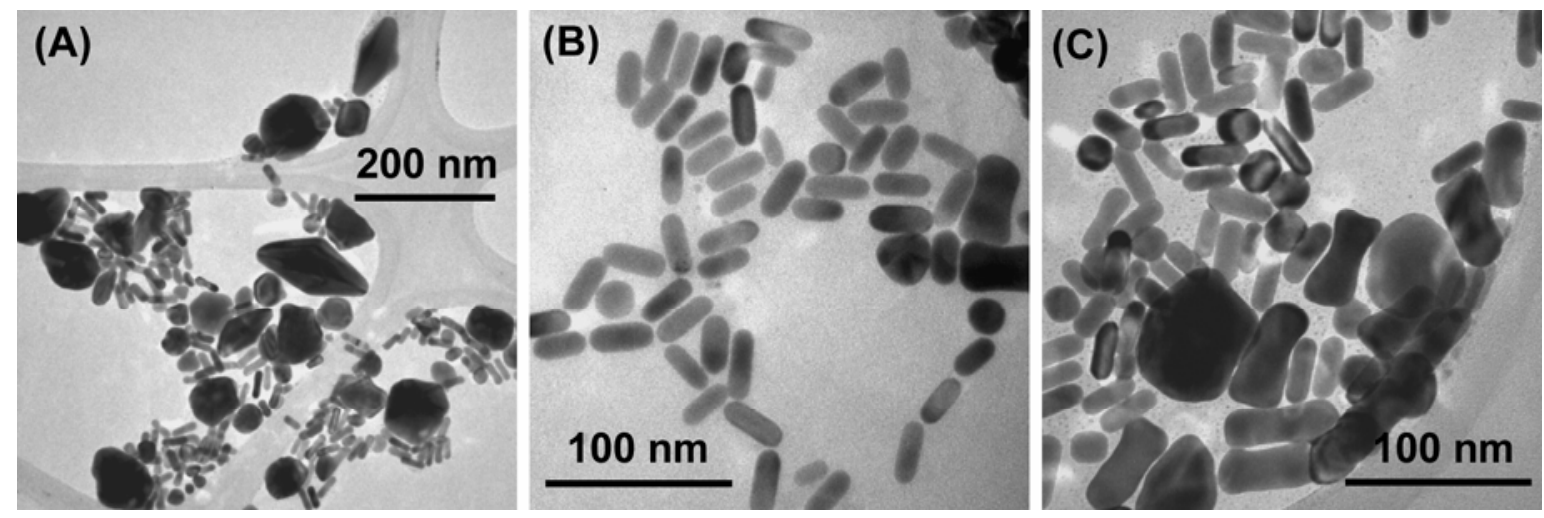

Figure S8. (A) TEM image of the growth products obtained by the addition of $10 \mathrm{~mL}$ of the growth solution into $2.5 \mathrm{~mL}$ of the original Au nanorod solution containing $100 \mu \mathrm{M} 11$ mercaptoundecanoic acid. (B) and (C) TEM images of the growth products obtained by the addition of $5 \mathrm{~mL}$ of the growth solution into $2.5 \mathrm{~mL}$ of the original $\mathrm{Au}$ nanorod solution containing $300 \mu \mathrm{M}$ 11-mercaptoundecanoic acid.
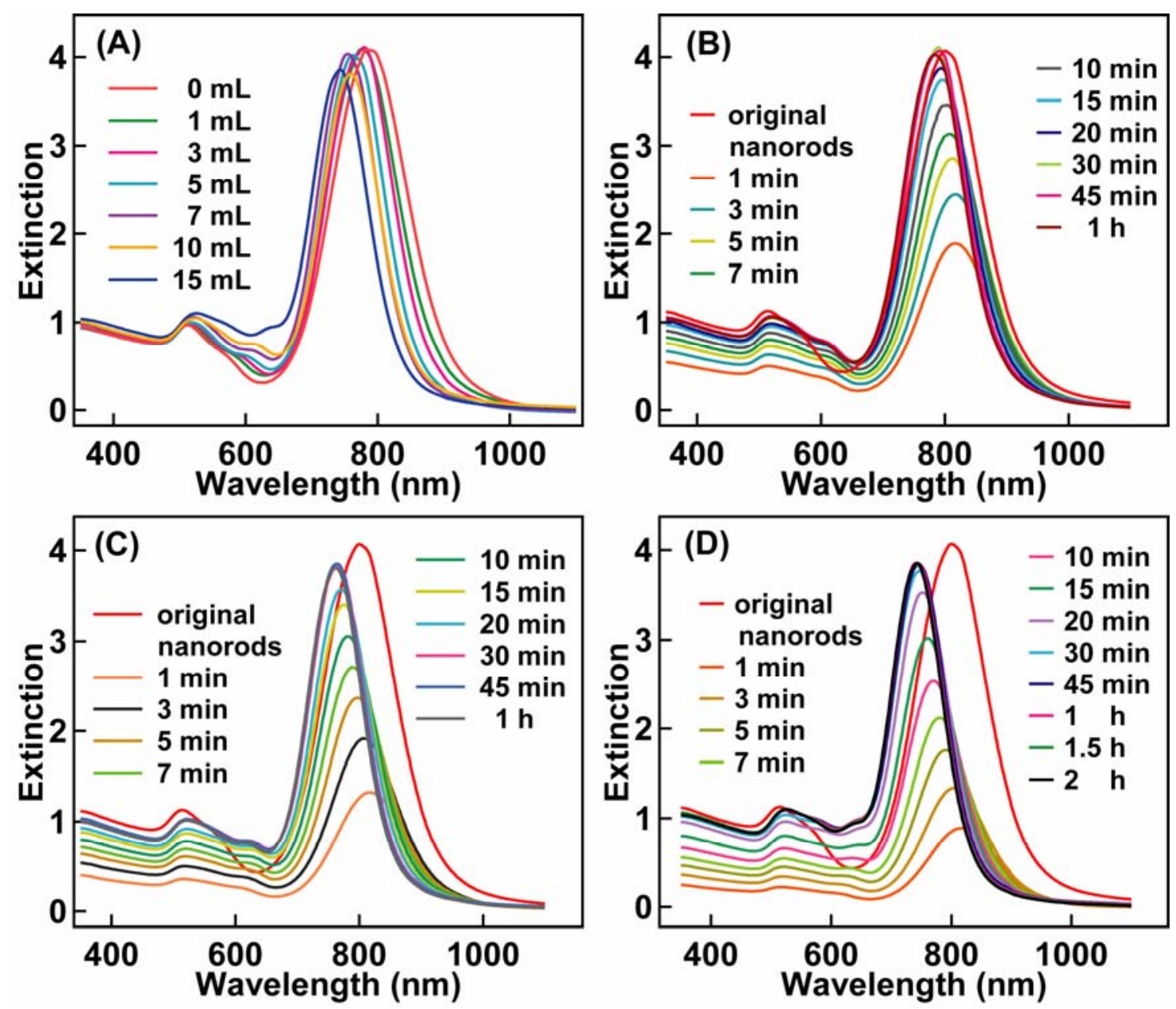

Figure S9. (A) Extinction spectra of the growth products obtained by the addition of varying volumes of the growth solution into $2.5 \mathrm{~mL}$ aliquots of the original Au nanorod solution. (B), 
(C), and (D) Time-dependent extinction spectra recorded after 5, 10, and $15 \mathrm{~mL}$ of the growth solution were added into $2.5 \mathrm{~mL}$ aliquots of the original Au nanorod solution, respectively.
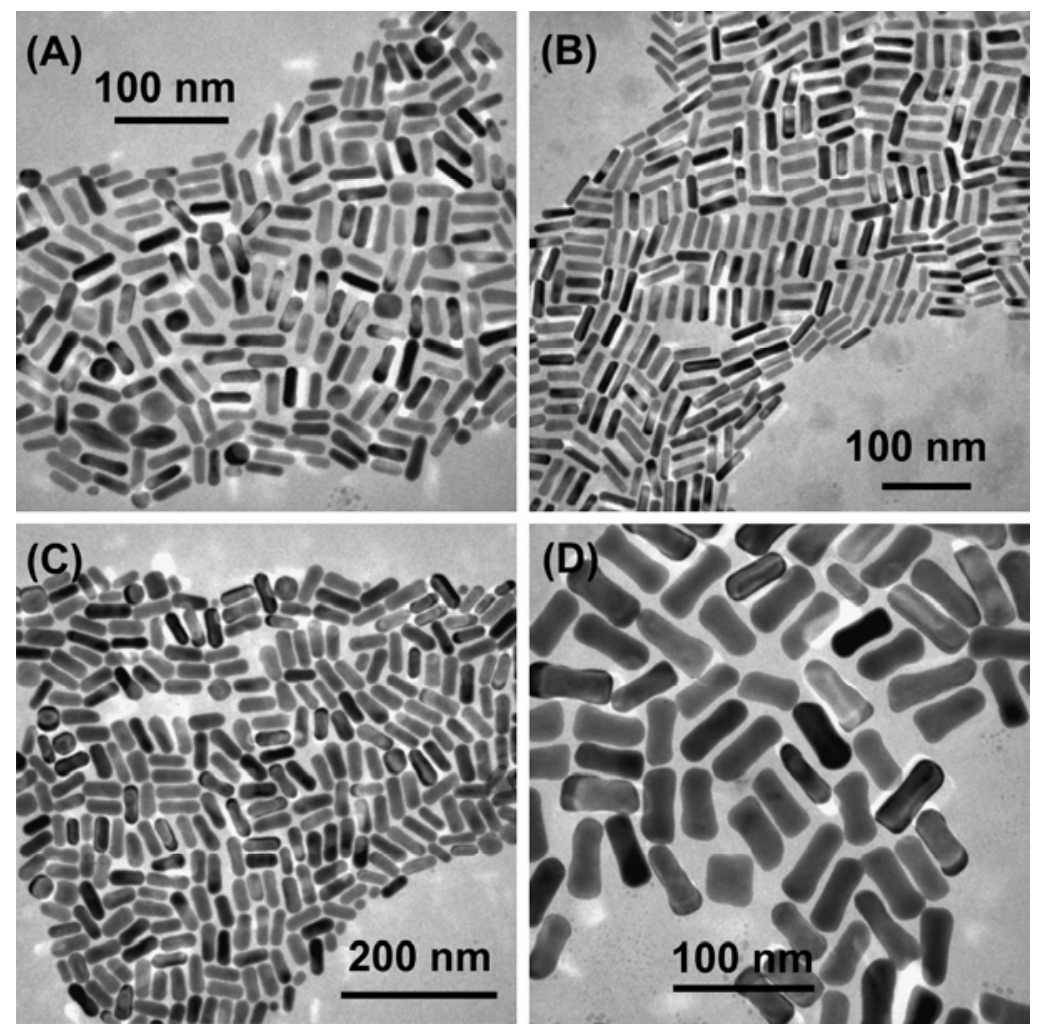

Figure S10. (A) TEM images of the original Au nanorods. (B) TEM images of the Au nanorods obtained by the addition of $3 \mathrm{~mL}$ of the growth solution into $2.5 \mathrm{~mL}$ of the original Au nanorod solution. (C) TEM images of the Au nanorods obtained by the addition of $7 \mathrm{~mL}$ of the growth solution into $2.5 \mathrm{~mL}$ of the original Au nanorod solution. (D) TEM images of the Au nanorods obtained by the addition of $15 \mathrm{~mL}$ of the growth solution into $2.5 \mathrm{~mL}$ of the original Au nanorod solution. 